\title{
Process Capability Indices under Non-Normality Conditions using Johnson Systems
}

\author{
Dr. Suboohi Safdar ${ }^{1}$, Dr. Ejaz Ahmed ${ }^{2}$, Dr. Tahseen Ahmed Jilani ${ }^{3}$, Dr. Arfa Maqsood ${ }^{4}$ \\ Department of Statistics, University of Karachi, Karachi, Pakistan ${ }^{1,4}$ \\ Computer Science \& Information Systems ${ }^{2}$ \\ Karachi Institute of Business Management, Karachi, Pakistan \\ School of Computer Science, University of Nottingham, Nottingham, $\mathrm{UK}^{3}$
}

\begin{abstract}
Process capability indices (PCIs) quantify the ability of a process to produce on target and within specifications performances. Basic indices designed for normal processes gives flawed results for non-normal process. Numerous methods have been proposed for non-normal processes to estimate PCIs in which some of them are based on transformation methods. The Johnson system comprising three types that translate a continuous non-normal distribution to normal. The aim of this paper is to estimate four basic indices for non-normal process using Johnson system with single straightforward procedure. The efficacy of the proposed approach can be assessed for all three Johnson Curves $\left(S_{B}, S_{U}, S_{L}\right)$ but result for $\mathbf{S}_{\mathbf{U}}$ is presented in

this paper. PCIs for a data set are estimated and percentiles are obtained by our proposed exact method based on selected Johnson density function which was earlier based on approximate methods without any prior knowledge of density function of non-normal process. We compare our results with other existing methods to estimate PCIs for non-normal process. From statistical analysis we have noted that this modification improve process capability indices.
\end{abstract} method

Keywords-Johnson curve; percentiles; simulation; exact

\section{INTRODUCTION}

Process capability analysis is conducted for a process which necessitate two conditions; first a controlled process and second the requirements pre-determined by product designer. Much of work has been performed for estimating PCIs for normal processes but these PCIs are inappropriate for non-normal because the estimators of PCIs for normal processes are not enough sufficient to characterize non-normal processes and deceive results. Several methods have been developed for PCIs of non-normal processes. Examples are Bates [1] discussed robustness of indices based on normal population, Pyzdek [2,3] showed that for non-normal processes standard process capability indices will give false process fallout rates and misled the results. Rivera [4] discussed $\mathrm{C}_{\mathrm{pk}}$ index estimation using transformation technique. Safdar and Ahmed [5, 6] proposed procedures for estimating PCIs for non-normal processes and obtained capability estimates based on Weibull shape parameter. PiñaMonarrezet.al [7] extended their work for estimating indices for Weibull and Lognormal distributions.

More precisely two basic approaches are discussed so far in published literature to estimate PCIs for non-normal processes. First, translate non-normal process to normal using transformation and estimate PCIs from any existing method designed for normal processes. Few popular transformation methods are Burr percentile method [8], Johnson method [9] Box-Cox power transformation method [10] and Montgomery square root transformation method [11] Second approach to estimate PCIs is based on percentile methods and most applied is Clements percentile method [12]. His method is based on percentiles as process parameters to estimate $C_{p}$ and $C_{p k}$ indices for non-normal processes. Pearn and Kotz [13] extended his work for $\mathrm{C}_{\mathrm{pm}}$ and $\mathrm{C}_{\mathrm{pmk}}$ indices. Pearn and Chan [14] generalized a superstructure for all of these four indices. Zwick [15] Schneider and Pruett [16] and Chen [17-20] suggested various PCIs for non-normal processes.

In this present article we estimated PCIs for non-normal process under Johnson system of distribution. We presented one distribution $\mathrm{S}_{\mathrm{U}}$ for estimating PCIs for non-normal data set of 100 measurements for a hypothetical process [21]. Our prime focus in this paper is to propose a uniform straightforward and easy approach to estimate PCIs for nonnormal processes. We estimated these PCIs from Pearn and Chan [14] superstructure using Johnson system and the percentiles $(0.00135,0.5$ and 0.99865$)$ of non-normal processes for the superstructure are obtained from best fitted Johnson density function whereas Pearn and Chan [14] estimated these percentiles as the percentage points of nonnormal processes.

We also emphasis on three assumptions of statistical process control (SPC) tools; First to manage the process in statistical control; second the parameters of the selected Johnson density function adequately fits the data and last the normality assumptions for the selected Johnson curve should not violated.

The paper structure is as follows: Section II presents existing PCIs for non-normal processes. Section III and IV briefly explains Johnson system of distribution and existing PCIs under Johnson distributions. In Section IV new capability computation procedures for non-normal distribution under Johnson system are proposed. Section VI comprehensively gives steps for obtaining modified PCIs using Johnson system with a brief flow chart. Section VII illustrates the proposed method explain with one example. After illustration of the proposed procedure a conclusion is made. 


\section{EXISTING PCIS FOR NON-NORMAL PROCESSES USING PEARSONIAN SYSTEM}

For normal processes Vannman [22] constructed a superstructure form for four basic indices $C_{p}, C_{p k}, C_{p m}$ and $C_{p m k}$

$C_{P}(u, v)=\frac{d-u|\mu-m|}{3 \sqrt{\sigma^{2}+v(\mu-T)^{2}}} \quad u \geq 0 ; v \geq 0$

Such that,

$$
C_{P}(0,0)=C_{p}, C_{P}(1,0)=C_{p k}, C_{P}(0,1)=C_{p m} \text { and } C_{P}(1,1)=C_{p m k}
$$

In this superstructure $\mu$ and $\sigma$ are the process mean and process standard deviation respectively, $\mathrm{T}$ is target value, $\mathrm{d}=$ (USL-LSL)/ 2 is half length of specification interval and $\mathrm{m}=$ (USL+LSL)/2 is the midpoint between upper and lower specification limits.

The basic indices $C_{p}, C_{p k}, C_{p m}$ and $C_{p m k}$ are proved inappropriate for non-normal processes because for nonnormal $\mu$ and $\sigma$ are not enough sufficient for non-normal process further the distribution of sample variance is sensitive to departure from normality. To accommodate the cases where the underlying distribution may not be normal Clements [12] proposed estimation of $\mathrm{C}_{\mathrm{p}}$ and $\mathrm{C}_{\mathrm{pk}}$ indices using other process parameters which are not sensitive to normality. He replaced 6 $\sigma$ of $\mathrm{C}_{\mathrm{p}}$ by length of interval between upper and lower 0.135 percentage points of non-normal data and process mean $\mu$ of $\mathrm{C}_{\mathrm{pk}}$ by 0.5 percentage point-median of the data set. Pearn and Kotz [13] applied Clements method to estimate $C_{p m}$ and $C_{p m k}$ indices and Pearn and Chan [14] constructed a superstructure to design indices for non-normal processes as;

$$
C_{N P}(u, v)=\frac{d-u|M-m|}{3 \sqrt{\left(\frac{F_{99.865}-F_{0.135}}{6}\right)^{2}+v(M-T)^{2}}} u \geq 0 ; v \geq 0
$$

Such that $C_{N P}(0,0)=C_{N p}, C_{N P}(1,0)=C_{N p k}, C_{N P}(0,1)=C_{N p m}$ and $C_{N P}(1,1)=C_{N p m k}$. WhereF $F_{0.135}, \mathrm{M}$ and $\mathrm{F}_{0.99865}$ are the $0.135^{\text {th }}, 0.5^{\text {th }}$ and $0.99865^{\text {th }}$ percentage points of non-normal processes under Pearsonian system respectively. Zwick [15] and Schneider et al. [16] considered two generalizations of $C_{p}$ and $\mathrm{C}_{\mathrm{pk}}$ but they used process mean $\mu$ rather than process median M. Chang and Lu [23] applied Clements method to obtain percentiles for $C_{N p}, C_{N p k}, C_{N p m}$ indices. Extending their methods Pearn and Chan [14] constructed another superstructure and obtained percentiles based on order statistics;

$$
\hat{C}_{N p}(u, v)=\frac{d-u|\hat{M}-m|}{3 \sqrt{\left[\frac{\hat{F}_{99.865}-\hat{F}_{0.135}}{6}\right]^{2}+v(\hat{M}-T)^{2}}} \quad u \geq 0, v \geq 0
$$

Such that

$$
\begin{aligned}
& \hat{C}_{N P}(0,0)=\hat{C}_{N p}, \hat{C}_{N P}(1,0)=\hat{C}_{N p k} \hat{C}_{N P}(0,1)=\hat{C}_{N p m} \text { and } \\
& C_{N P}(1,1)=C_{N p m k} \\
& \hat{F}_{0.135}=X_{\left(R_{2}\right)}+\left(\left[\frac{(0.135) n+0.99865}{100}\right]-R_{2}\right) \times\left(X_{\left(R_{2}+1\right)}-\left(X_{\left(R_{2}\right)}\right)\right) \\
& \hat{M}=X_{\left(R_{3}\right)}+\left(\left[\frac{n+1}{2}\right]-R_{3}\right) \times\left(X_{\left(R_{3}+1\right)}-\left(X_{\left(R_{3}\right)}\right)\right) \\
& \hat{F}_{99.865}=X_{\left(R_{1}\right)}+\left(\left[\frac{(99.865) n+0.135}{100}\right]-R_{1}\right) \times\left(X_{\left(R_{1}+1\right)}-\left(X_{\left(R_{1}\right)}\right)\right)
\end{aligned}
$$

Where $\quad \mathrm{R}_{1}=\quad[(99.865 \mathrm{n}+0.135) / 100], \quad \mathrm{R}_{2}=$ $[(0.135 n+99.865) / 100]$ and $R_{3}=[(n+1) / 2]$. In this setting, the notation $[\mathrm{R}]$ is defined as the greatest integer less than or equal to the number $\mathrm{R}$ and $x_{(i)}$ is defined as $i^{\text {th }}$ order statistic.

Pearn and Kotz [13] and Pearn and Chen [24] applied Clements [12] method to estimate PCIs of non-normal processes. The PCIs in which those estimators correspond to can be expressed as

$$
\begin{aligned}
& \left.C_{N p}^{\prime}(u, v)\right)=(1-u) \times \frac{U S L-L S L}{6 \sqrt{\left[\frac{F_{99865}-F_{0.135}}{6}\right]^{2}}+v(M-T)^{2}}+u \times
\end{aligned}
$$

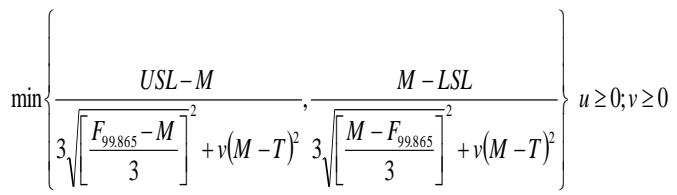

Such that $C_{N p}^{\prime}(0,0)=C_{N p}^{\prime}, C_{N p}^{\prime}(1,0)=C_{N p k}^{\prime}, C_{N p}^{\prime}(0,1)=C_{N p m}^{\prime}$ and $C_{N p}^{\prime}(1,1)=C_{N p m k}^{\prime}$

Equations (1) to (4) are the existing superstructures to estimate PCIs for wide range of processes. Now we briefly describe the Johnson system of distributions and existing methods to estimate PCIs for non-normal processes in Section III.

\section{JOHNSON SYSTEM OF DISTRIBUTION}

The Johnson system of frequency curve was first developed by Johnson [9]. Farnum [21] has given a detailed description on the use of Johnson Curves. Chou et al [25] and Polansky et al. [26] proposed Johnson system of distribution to transform non-normal data sets. For complete description of this system, see Bowman Shenton [27], Johnson, Kotz and Balakrishnan [28]' Stuart and Ord [29] and Kendall and Stuart [30]

Briefly, there are three distributions $\left(S_{B}, S_{U}, S_{L}\right)$ of Johnson curves having two shape ( $\gamma$ and $\eta$ ), one location $(\varepsilon)$ and one scale $(\lambda)$ real parameters. $S_{B}$ cover bounded distributions as gamma, beta and other distributions. It is bounded on lower end by $\varepsilon$, upper end by $\varepsilon+\lambda$ or both. $\mathrm{S}_{\mathrm{U}}$ are unbounded and cover $\mathrm{t}$ and normal distributions. $\mathrm{S}_{\mathrm{L}}$ covers $\log$-normal family and bounded only lower side by $\mathcal{E}$.

These three distributions are generated by transformations of the form 
$z=\gamma+\eta k_{i}(x ; \lambda, \varepsilon)$

Where $k_{i}(x ; \lambda, \varepsilon)$ are chosen to cover a wide range of possible shapes and $\mathrm{z}$ is a standard normal variable. Johnson suggested these following functions for each distribution:

$k_{1}(x ; \lambda, \varepsilon)=\ln \left(\frac{x-\varepsilon}{\lambda+\varepsilon-x}\right) \quad$ For $\mathrm{S}_{\mathrm{B}}$ distribution

$k_{2}(x ; \lambda, \varepsilon)=\sinh ^{-1}\left(\frac{x-\varepsilon}{\lambda}\right) \quad$ For $\mathrm{S}_{\mathrm{U}}$ distribution

$k_{3}(x ; \lambda, \varepsilon)=\ln \left(\frac{x-\varepsilon}{\lambda}\right) \quad$ For $\mathrm{S}_{\mathrm{L}}$ distribution

The three well known methods of estimation the parameters of Johnson System are the moment matching method by Draper [31], the percentile matching method by Slifker and Shapiro [32] and the quantile estimation method by Wheeler [33].

Table I comprises Johnson distributions $\left(S_{B}, S_{U}, S_{L}\right)$ for $\mathrm{X}$ (Johnson variate) and (Standard normal Johnson variates). In Section IV we summarize the earlier developed methods to estimate PCIs using Johnson system for non-normal distributions.

\section{EXISTING PCIS FOR NON-NORMAL DISTRIBUTION USING JOHNSON SYSTEM}

For normal processes the indices $\mathrm{C}_{\mathrm{p}}$ and $\mathrm{C}_{\mathrm{pk}}$ are defined as;

$C_{p}=\frac{U S L-L S L}{(\mu+3 \sigma)-(\mu-3 \sigma)}=\frac{U S L-L S L}{6 \sigma}$

$C_{p k}=\frac{\min \{U S L-\mu, \mu-L S L\}}{3 \sigma}$

Pyzdek [2] worked on measurements of a hypothetical process to illustrate the use of Johnson transformation and fitted $S_{B}$ curve. He used $\lambda$ (the scale parameter of $S_{B}$ curve) as process spread $6 \sigma$ with the reason that difference between lower $\varepsilon$ and upper bound $\varepsilon+\lambda$ of the curve $(\varepsilon+\lambda)-\varepsilon$ may use as process spread.

$C_{p}=\frac{U S L-L S L}{(\varepsilon+\lambda)-(\varepsilon)}=\frac{U S L-L S L}{\lambda}$

Farnum [21] obtained $\mathrm{C}_{\mathrm{p}}$ and $\mathrm{C}_{\mathrm{pk}}$ using Johnson system and fitted $\mathrm{S}_{\mathrm{U}}$ curve. He replaced process spread $6 \sigma$ by $U_{p}-L_{p}$ for non-normal process and found $L_{p}$ and $U_{p}$ by putting $\mathrm{z}=-3$ and $\mathrm{z}=3$ in equation of $\mathrm{x}$ for $\mathrm{S}_{\mathrm{U}}$ curve (as displayed in Table I). These two indices are defined as:

$C_{p}=\frac{U S L-L S L}{U_{p}-L_{p}}$

$C_{p k}=\min \left\{\frac{U S L-M}{U_{p}-M}, \frac{M-L S L}{M-L_{p}}\right\}$

Extending Equation (8) the two other PCIs for non-normal processes under Johnson distribution are

$C_{p m}=\frac{U S L-L S L}{6 \sqrt{\left[\frac{U_{p}-L_{p}}{6}\right]^{2}+\left(M-T^{2}\right)}}$

$C_{p m k}=\min \left\{\frac{U S L-M}{\sqrt[3]{\left[\frac{U_{p}-L_{p}}{6}\right]^{2}+\left(M-T^{2}\right)}}, \frac{3-L S L}{\sqrt{\left[\frac{U_{p}-L_{p}}{6}\right]^{2}+\left(M-T^{2}\right)}}\right\}$

Where $M$ is the average of $\left(L_{p}, U_{p}\right)$ and $T$ is target value specified by product designer. In Section $\mathrm{V}$ standardized method to estimate $\left(L_{p}, M, U_{p}\right)$ as process parameters for nonnormal processes with new capability computation procedure is presented.

TABLE I. JOHNSON CURVES FOR X \& Z VARIABLE

\begin{tabular}{|c|c|c|}
\hline Johnson curve & $\mathrm{X}$-variate & Z-variate \\
\hline Bounded $S_{B}$ & $\varepsilon+\frac{\lambda}{1+e^{-\left(\frac{z-\gamma}{\eta}\right)}}$ & $\gamma+\eta \log \left(\frac{x-\varepsilon}{\lambda+\varepsilon-x}\right)(\varepsilon<x<\varepsilon+\lambda)$ \\
\hline Unbounded $\mathrm{S}_{\mathrm{U}}$ & $\varepsilon+\lambda \sinh \left(\frac{z-\gamma}{\eta}\right)$ & $\gamma+\eta \sinh ^{-1}\left(\frac{x-\varepsilon}{\lambda}\right)(-\infty<x<\infty)$ \\
\hline Lognormal $S_{L}$ & $\varepsilon+\exp \left(\frac{z-\gamma}{\eta}\right)$ & $\gamma+\eta \log (x-\varepsilon) \quad(\varepsilon<x)$ \\
\hline
\end{tabular}




\section{NEW CAPABILITY CALCULATION FOR NON-NORMAL DISTRIBUTION UNDER JOHNSON SYSTEM}

A uniform SPC based procedure is presented to estimate PCIs for non-normal processes under Johnson system. We used superstructure form of Pearn and Chan [14] to estimate PCIs based on Johnson distributions.

For our new capability calculations we estimate these percentiles using density function $f(x)$ of selected Johnson distribution which is found to be the best fit for the given nonnormal data set.

$$
\begin{aligned}
& \int_{-\infty}^{\hat{F}_{0.135}} f(x) d x=0.00135 \\
& \int_{-\infty}^{\hat{F}_{99865}} f(x) d x=0.99865 ; \\
& \int_{-\infty}^{M} f(x) d x=0.5
\end{aligned}
$$

Based on our new capability calculations we named our capability indices as JPCI in computation tables.

Now we illustrate our procedure in steps to estimate PCIs easily.

\section{STEPS FOR OBTAINING MODIFIED PCIS USING JOHNSON SYSTEMS}

The following steps are made for the proposed method.

Step 1: For the given data set obtain proportion nonconforming NC, process yield\% and Vannman PCIs from Equation (1).

Step 2: Check whether process parameters $(\mu, \sigma)$ of Vannman superstructure misled the results. If no, there is no need to transform and if yes transform data set using Johnson transformation to select best fitted curve from $\left(S_{L}, S_{B}, S_{U}\right)$

Step 3: Superimpose the original and Johnson based fitted curve on probability histogram of original nonnormal data sets to show that the chosen Johnson curve adequately fits the data.

Step 4: Simulate samples of size $\mathrm{n}=49,99,199,499,999$, 1499 and 1999 for the fitted Johnson curve.

Step 5: From each simulated sample count (if any) number of observation(s) beyond the specification limits and exclude them for a statistical controlled process. Construct a grouped frequency distribution of controlled samples and apply chi-square goodness of fit test to asses that new samples are from the fitted Johnson distribution

Step 5: Transform $\mathrm{x}$ variates and predetermined specification limits $(L S L, U S L)$ of fitted Johnson curve in standard normal $_{Z}=\frac{x-\mu}{\sigma}$ as $\left(Z_{l}, Z_{u}\right)$. Estimate proportion of process measurements, that exceeds the specification limits as $\left(p_{l}, p_{u}\right)$. Find $0.135^{\text {th }}, 0.5^{\text {th }}$ and $0.99865^{\text {th }}$ percentage points $\left(\hat{F}_{0.135}, \hat{F}_{99.865}\right)$ for each data set by Farnum and based on our new computation procedure from the Johnson density function.

Step 6: For graphical assessment of normality construct probability histogram and draw normal probability plot (NPP) for each sample. For statistical assessment apply Shapiro-Wilk normality test for $\mathrm{x}$ and $\mathrm{z}$ variates.

Step 7: Estimate indices using Johnson system named as JPCI based on our computation procedure using superstructure from Equation (3) and percentiles for superstructure from Equation (10), John (Z) by Pyzdek and Farnum method from Equations (8) and (9). We also estimates PCIs by existing methods under Pearson distribution to check the efficacy of our method; Clements from Equation (2), Pearn and Chan from Equation (3), Pearn-Kotz-Chan from Equation (4).

\section{ILLUSTRATION OF PROPOSED METHOD}

For illustration of proposed method the data consist of 100 measurements from a process earlier presented by Farnum [21] is taken. See Table II.

First we estimate the PCIs assuming that observations come from normal distribution for the given hypothetical process.

From Table III, we observe that PCIs assuming normal population are not satisfactory and misleading. We must use PCIs designed for non-normal processes. The best fitted equation as Farnum [21] found for data set is $S_{U}$

TABLE II. 100 MEASUREMENT OF PROCESS ( $\mathrm{LSL}=5$, USL=40, T=22.5)

\begin{tabular}{|l|l|l|l|l|l|l|l|l|l|}
\hline 6.3 & 6.8 & 9.3 & 10.4 & 11.1 & 11.6 & 12.2 & 12.5 & 12.5 & 12.6 \\
\hline 12.9 & 13.2 & 13.2 & 13.3 & 13.3 & 13.5 & 13.5 & 13.9 & 14 & 14.4 \\
\hline 14.8 & 14.8 & 15.2 & 15.4 & 15.7 & 15.8 & 15.9 & 16.2 & 16.3 & 16.5 \\
\hline 16.5 & 16.7 & 16.9 & 17 & 17.1 & 17.7 & 17.8 & 17.9 & 18 & 18.1 \\
\hline 18.1 & 18.1 & 18.1 & 18.1 & 18.1 & 18.4 & 18.4 & 18.7 & 18.7 & 18.8 \\
\hline 19.1 & 19.3 & 19.3 & 19.5 & 19.6 & 19.7 & 19.7 & 19.9 & 20.2 & 20.3 \\
\hline 20.6 & 20.6 & 20.7 & 20.8 & 21.4 & 21.5 & 21.9 & 22 & 22 & 22.1 \\
\hline 22.3 & 22.6 & 22.7 & 22.9 & 23 & 23.3 & 23.3 & 23.5 & 24 & 24.2 \\
\hline 24.7 & 25 & 25.1 & 25.5 & 25.5 & 25.7 & 25.9 & 26 & 26.1 & 29.3 \\
\hline 29.4 & 29.6 & 29.6 & 29.8 & 29.9 & 29.9 & 31.4 & 34 & 34.9 & 40.6 \\
\hline
\end{tabular}

TABLE III. PCIS ASSUMING NORMAL PROCESS

\begin{tabular}{|l|l|l|l|}
\hline PCIs & Normal based PCIs & NC\% & Process Yield\% \\
\hline$C_{p}$ & 0.957 & 0.41 & $99.59<99.73$ \\
\hline$C_{p k}$ & 0.806 & 1.56 & $98.44<99.73$ \\
\hline$C_{p m}$ & 0.872 & 0.89 & $99.11<99.73$ \\
\hline$C_{p m k}$ & 0.734 & 2.77 & $97.23<99.73$ \\
\hline
\end{tabular}


$Z=-1.767+2.519 \sinh ^{-1}\left(\frac{x-10.942}{10.826}\right) ;(-\infty<x<\infty)$

The $\mathrm{S}_{\mathrm{U}}$ distribution is an unbounded distribution so both transformed limits are possible for each sample. Now we constructed histogram for the data set and superimpose the fitted Johnson curve.

Fig. 1 shows that fitted Johnson curve adequately fits the original data.

For each simulated sample histograms and normal probability plots NPP are drawn to graphical examine the adequacy of model and normality assumption, see Fig. 2.

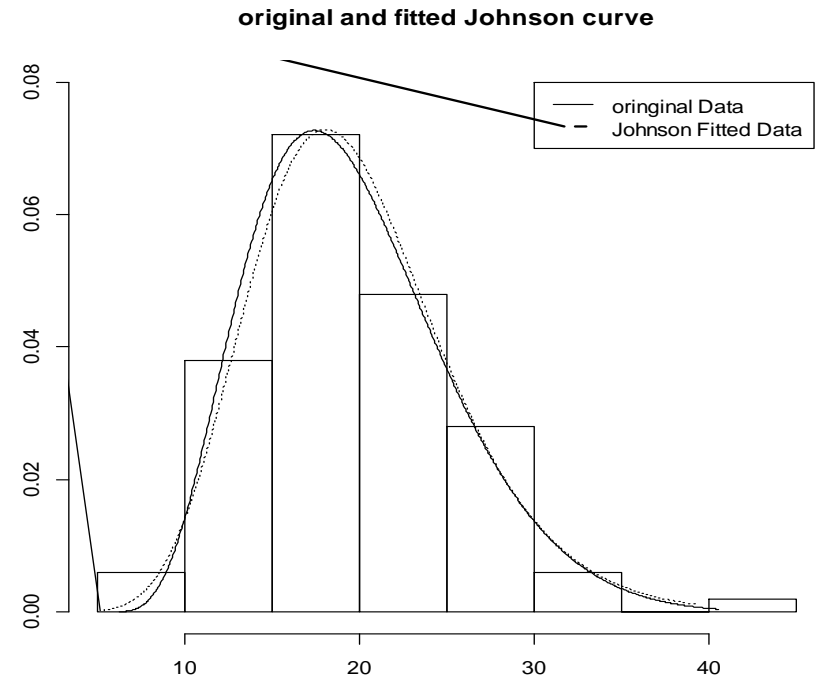

Fig. 1. Original and Best Fitted Johnson Curve with Probability Histogram.
For statistical test of normality Shapiro-Wilk normality test is performed and results are comprised in Table IV.

For original data and each sample transformed limits for $\mathrm{S}_{\mathrm{U}}$, proportion of non-conforming (NC) and $0.135^{\text {th }}, 0.5^{\text {th }}$ and $0.99865^{\text {th }}$ percentiles (for Farnum method and our proposed method) are obtained. The results are given in Table V.

From Table VI, it is observed that capability calculations proposed under Johnson system for $S_{\mathrm{u}}$ distribution improve indices with those obtained by Pyzdek and Farnum theories using Johnson system and other existing methods under Pearsonion system.

TABLE IV. SHAPIRO-WILK NORMALITY TEST

\begin{tabular}{|l|l|l|l|}
\hline Sample Size & Type & SW Statistics & P-value \\
\hline \multirow{3}{*}{ Original data } & $\mathbf{X}$ & 0.975 & 0.055 \\
\cline { 2 - 4 } & $\mathbf{Z}$ & 0.994 & 0.938 \\
\hline \multirow{4}{49}{} & $\mathbf{X}$ & 0.980 & 0.545 \\
\cline { 2 - 4 } & $\mathbf{Z}$ & 0.972 & 0.281 \\
\hline \multirow{2}{*99}{} & $\mathbf{X}$ & 0.973 & 0.040 \\
\cline { 2 - 4 } & $\mathbf{Z}$ & 0.975 & 0.055 \\
\hline \multirow{2}{*}{199} & $\mathbf{X}$ & 0.971 & 0.000 \\
\cline { 2 - 4 } & $\mathbf{Z}$ & 0.988 & 0.099 \\
\hline \multirow{4}{4}{499} & $\mathbf{X}$ & 0.976 & 0.000 \\
\hline \multirow{3}{*}{$\mathbf{9 9 9}$} & $\mathbf{Z}$ & 0.993 & 0.017 \\
\hline \multirow{2}{*}{$\mathbf{4 9 9}$} & $\mathbf{X}$ & 0.976 & 0.000 \\
\cline { 2 - 4 } & $\mathbf{Z}$ & 0.993 & 0.000 \\
\hline \multirow{2}{*}{$\mathbf{9 9 9}$} & $\mathbf{X}$ & 0.983 & 0.017 \\
\cline { 2 - 4 } & $\mathbf{Z}$ & 0.997 & 0.010 \\
\hline
\end{tabular}

TABLE V. ORIGINAL AND TRANSFORMED SPECIFICATION Limits, NC (PPM) AND PERCENTILES

\begin{tabular}{|c|c|c|c|c|c|}
\hline Size & (USL,LSL) & $\begin{array}{l}\text { Transformed } \\
\text { Limits in } \mathbf{Z}\end{array}$ & $\begin{array}{l}\text { NC } \\
\text { PPM }\end{array}$ & $\begin{array}{l}\left(\mathbf{L}_{\mathbf{p}}, \mathbf{U}_{\mathbf{p}}\right) \\
(\text { Farnum) }\end{array}$ & $\begin{array}{l}\left(\mathbf{L}_{\mathrm{p}}, \mathrm{U}_{\mathrm{p}}\right) \\
\text { (Our method) }\end{array}$ \\
\hline \multirow{2}{*}{$\begin{array}{l}\text { original } \\
\text { data }\end{array}$} & \multirow{2}{*}{$(5,40)$} & -6.356 & 0 & 8.13 & 13.83 \\
\hline & & 3.034 & 1206 & 39.76 & 46.04 \\
\hline \multirow{2}{*}{49} & \multirow{2}{*}{$(5,40)$} & -2 & 22750 & -5.1 & 14.96 \\
\hline & & 3 & 1350 & 46.2 & 46.18 \\
\hline \multirow{2}{*}{99} & \multirow{2}{*}{$(5,40)$} & -2 & 22750 & -3.6 & 14.74 \\
\hline & & 2 & 22750 & 54.7 & 54.74 \\
\hline \multirow{2}{*}{199} & \multirow{2}{*}{$(5,40)$} & -3 & 1350 & 2.6 & 14.2 \\
\hline & & 2 & 22750 & 52.6 & 52.6 \\
\hline \multirow{2}{*}{499} & \multirow{2}{*}{$(5,40)$} & -3 & 1350 & 1.8 & 14.38 \\
\hline & & 2 & 22750 & 53.6 & 53.55 \\
\hline \multirow{2}{*}{999} & \multirow{2}{*}{$(5,40)$} & -3 & 1350 & 0.5 & 14.18 \\
\hline & & 2 & 22750 & 56 & 56 \\
\hline \multirow{2}{*}{1499} & \multirow{2}{*}{$(5,40)$} & -3 & 1350 & 4.1 & 13.85 \\
\hline & & 3 & 1350 & 46.8 & 46.8 \\
\hline \multirow{2}{*}{1999} & \multirow{2}{*}{$(5,40)$} & -3 & 1350 & 5 & 13.84 \\
\hline & & 3 & 1350 & 46.6 & 46.63 \\
\hline
\end{tabular}



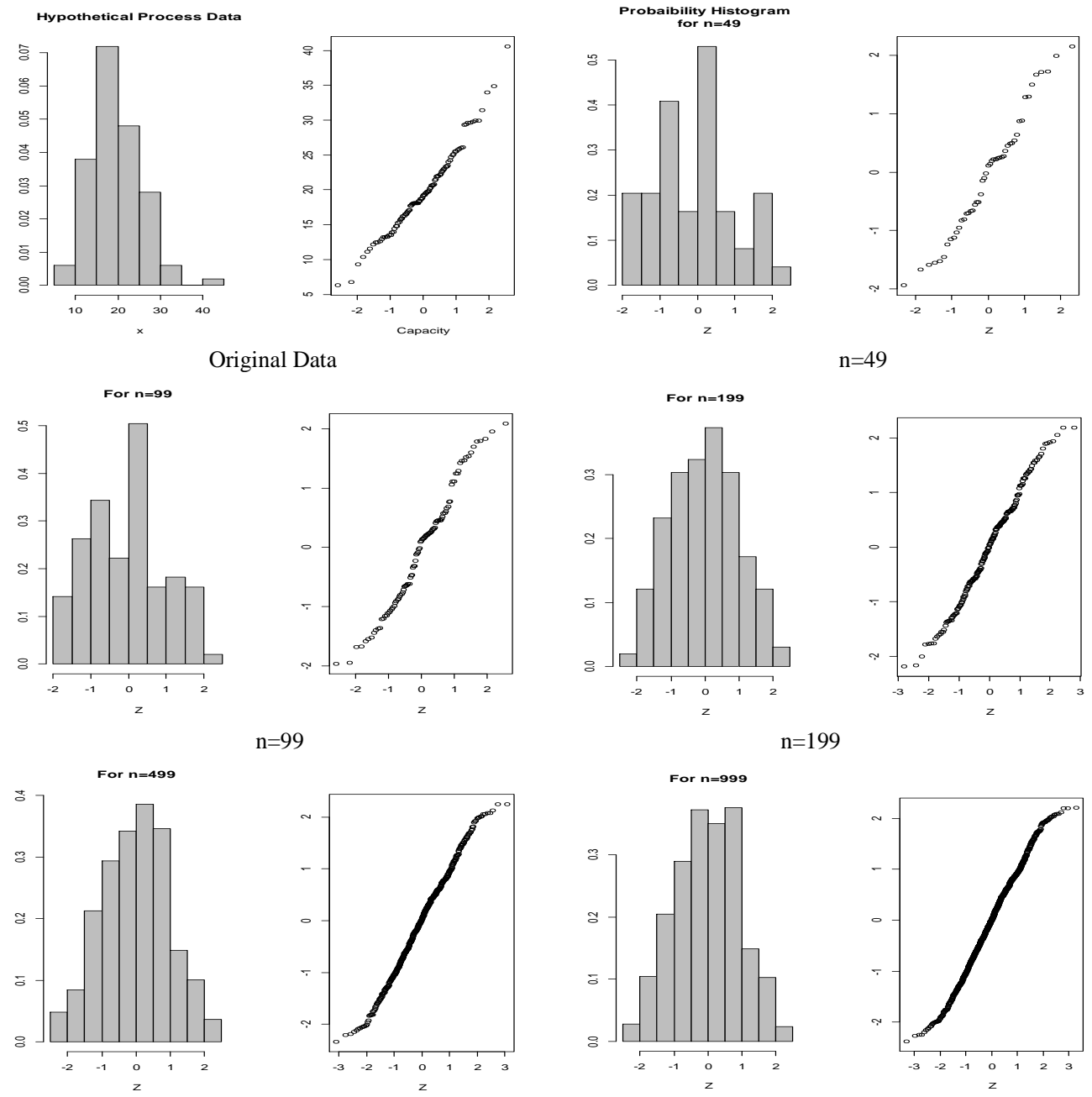

$\mathrm{n}=499$

$\mathrm{n}=999$
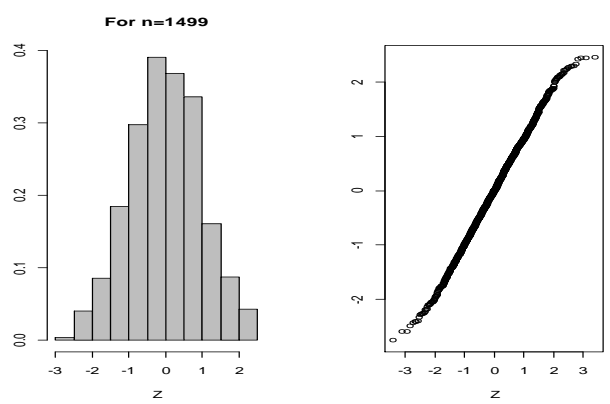

$\mathrm{n}=1499$
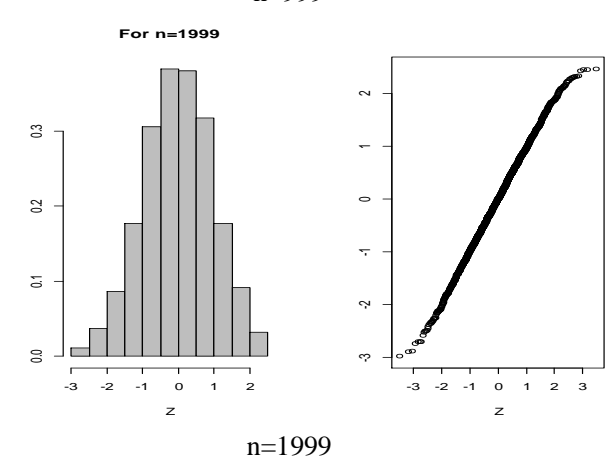

Fig. 2. Histogram and NPP of Best Fitted Johnson Curve. 
TABLE VI. PCIS UNDER JOHNSON SYSTEM FOR SU DISTRIBUTION

\begin{tabular}{|c|c|c|c|c|c|}
\hline Samples & Methods & Cp & Cpk & Cpm & Cpmk \\
\hline \multirow{6}{*}{ Original data } & PCI (Vannman) & 0.956 & 0.806 & 0.872 & 0.734 \\
\hline & John $(Z)($ Pyzdek and Farnum) & 0.862 & 0.704 & 0.779 & 0.637 \\
\hline & JPCIs (Modified) & 1.086 & 0.879 & 0.923 & 0.748 \\
\hline & Clements & 1.045 & 0.833 & 0.882 & 0.703 \\
\hline & Pearn \& Chen & 1.045 & 0.824 & 0.871 & 0.687 \\
\hline & PKC & 1.045 & 1.007 & 0.882 & 0.846 \\
\hline \multirow{5}{*}{$n=49$} & JPCIs & 1.121 & 1.051 & 1.097 & 1.029 \\
\hline & $\operatorname{John}(\mathbf{Z})$ & 0.682 & 0.607 & 0.666 & 0.594 \\
\hline & Clements & 1.278 & 1.241 & 1.27 & 1.234 \\
\hline & Pearn\& Chen & 1.278 & 1.241 & 1.27 & 1.234 \\
\hline & PKC & 1.278 & 1.254 & 1.27 & 1.246 \\
\hline \multirow{5}{*}{$\mathrm{n}=99$} & JPCIs & 0.875 & 0.816 & 0.862 & 0.804 \\
\hline & $\operatorname{John}(\mathbf{Z})$ & 0.6 & 0.495 & 0.572 & 0.471 \\
\hline & Clements & 1.144 & 1.111 & 1.138 & 1.106 \\
\hline & Pearn\& Chen & 1.144 & 1.111 & 1.138 & 1.106 \\
\hline & PKC & 1.144 & 1.065 & 1.138 & 1.061 \\
\hline \multirow{5}{*}{$n=199$} & JPCIs & 0.911 & 0.781 & 0.849 & 0.727 \\
\hline & $\operatorname{John}(Z)$ & 0.7 & 0.496 & 0.597 & 0.423 \\
\hline & Clements & 1.134 & 0.98 & 1.03 & 0.89 \\
\hline & Pearn\& Chen & 1.134 & 0.972 & 1.02 & 0.874 \\
\hline & PKC & 1.134 & 1.043 & 1.02 & 0.977 \\
\hline \multirow{5}{*}{$n=499$} & JPCIs & 0.894 & 0.745 & 0.816 & 0.68 \\
\hline & $\operatorname{John}(Z)$ & 0.676 & 0.475 & 0.579 & 0.407 \\
\hline & Clements & 1.123 & 0.946 & 0.991 & 0.835 \\
\hline & Pearn\& Chen & 1.123 & 0.946 & 0.991 & 0.835 \\
\hline & PKC & 1.123 & 1.044 & 0.991 & 0.96 \\
\hline \multirow{5}{*}{$\mathrm{n}=999$} & JPCIs & 0.837 & 0.687 & 0.764 & 0.628 \\
\hline & $\operatorname{John}(Z)$ & 0.631 & 0.425 & 0.537 & 0.362 \\
\hline & Clements & 1.102 & 0.906 & 0.95 & 0.78 \\
\hline & Pearn\& Chen & 1.102 & 0.906 & 0.95 & 0.78 \\
\hline & PKC & 1.102 & 1.042 & 0.95 & 0.942 \\
\hline \multirow{5}{*}{$n=1499$} & JPCIs & 1.062 & 0.867 & 0.917 & 0.749 \\
\hline & $\operatorname{John}(Z)$ & 0.82 & 0.684 & 0.759 & 0.633 \\
\hline & Clements & 1.074 & 0.876 & 0.923 & 0.753 \\
\hline & Pearn\& Chen & 1.074 & 0.875 & 0.923 & 0.753 \\
\hline & PKC & 1.074 & 1.044 & 0.923 & 0.892 \\
\hline \multirow{5}{*}{$n=1999$} & JPCIs & 1.067 & 0.869 & 0.917 & 0.747 \\
\hline & $\operatorname{John}(Z)$ & 0.841 & 0.683 & 0.76 & 0.616 \\
\hline & Clements & 1.065 & 0.867 & 0.916 & 0.745 \\
\hline & Pearn\& Chen & 1.065 & 0.867 & 0.916 & 0.745 \\
\hline & PKC & 1.065 & 1.053 & 0.916 & 0.87 \\
\hline
\end{tabular}




\section{DISCUSSION AND CONCLUSION}

The aim of this Paper is to focus attention on PCIs and their estimators and to emphasize their original basic purpose that of controlling the expected proportion outside specification limits based on engineering consideration. Earlier the percentiles of PCIs which are designed-modified for non-normal processes using Johnson system are estimated by approximate methods which do not require the knowledge of the density function of the data. We simulate the samples based on Johnson density function from the Johnson parameters estimated for the original non-normal process and then obtain the capability calculation for the indices. The percentiles of the PCIs are estimated by our modified method because the density function of the simulated samples is known.

In this paper we not only compare the results of PCIs based on Johnson systems with other existing methods for non-normal populations but list a program that can comprises the complete analysis step-by-step for choosing any of the Johnson curve. This program initially make the process in statistical control with the given specification limits, plot the density curve on original data to check the adequacy, and estimate PCIs based on new probability calculation as we execute the script for any non-normal or even normal data sets. All the computations are performed in R-console.

We observed in dealing with one non-normal data set that PCIs based on new probability calculation of simulated samples under Johnson system improve the indices estimated by Pyzdek and Farnum theories. We also noted 'over-thesample' variations in each simulated sample based on fitted Johnson curve. We performed our capability calculation based on Pearn and Chan superstructure and obtain percentiles by exact method of selected Johnson distribution not by approximate method. We have also observed that new capability calculation improve the indices.

\section{FURTHER RECOMMENDATIONS}

The authors are intended to do this program for estimating process capability indices for multivariate data.

\section{REFERENCES}

[1] Bates TE, English JR. The robustness of modern process capability analysis. Computers Ind. Eng.1991; 21:45 49.

[2] Pyzdek T. Process capability analysis using personal computers. Quality Engineering 1992; 4: 419-440.

[3] Pyzdek. Why Normal distributions aren't [All that Normal]. Quality Engineering 1995; 7: 769-777.

[4] Rivera LAR, Hubele NF, Lawrence FP. Cpk index estimation using data transformation. Computers Ind. Eng. 1995; 29: 55-58.

[5] Ahmed E, Safdar S. Process capability analysis for non- normal data. Pakistan Business Review 2010; 234-243.

[6] Safdar S, Ahmed E. Process capability indices for shape parameter of Weibull distribution. Open Journal of Statistics 2014; 4: 207-219. doi: 10.4236/ojs.2014.43020.

[7] Piña-MonarrezMR, Ortiz-Yañez JF, Rodríguez-Borbón MI. Non-normal capability indices for the Weibull and Lognormal Distributions. Quality and Reliability Engineering International 2016; 32:1321-1329. doi: 10.1002/qre.1832.

[8] Burr IW. Cumulative frequency distribution. Ann Math Stat. 1942; 13: 215-232.

[9] Johnson NL. System of frequency curves generated by translation. Biometrika, 1949; 36: 149-176.

[10] Box GEP, Cox DR. An analysis of transformation. Journal of Royal Statistical Society. 1964; 26: 211-243.

[11] Somerville SE, Montgomery DC. Process capability indices and Nonnormal distributions. Quality Engineering 1996-97; 19: 305-316.

[12] Clements JA. Process capability calculations for Non-normal distributions. Quality Progress. 1989 September, 95-100.

[13] Pearn WL, Kotz. S. Application of Clements' method for calculating second and third generation process capability indices for no-normal Pearsonian populations. Quality Engineering 1994; 7: 139-145.

[14] Pearn WL, Chan KS. Capability indices for non-normal distributions with an application in electrolytic capacitor manufacturing. Microelectronics Reliability Engineering. 1997; 37: 1853-185

[15] Zwick D. A hybrid method for fitting distributions to data and it use in computing process capability indices. Quality Engineering.1995; 7: 601613.

[16] Schneider and Pruett J. Uses of process capability indices in the supplier certification process. Quality Engineering (1995-96); 9: 225-235.

[17] Chen KS. Process capability indices for skew populations. Journal of Management and Systems. 1996; 3: 207-216.

[18] Chen KS. A new process capability index for asymmetric tolerances. Journal of the Chinese Institute of Industrial Engineers. 1997; 14: 355362.

[19] Chen KS. Incapability index with asymmetric tolerance. Statistica Sinica. 1998;8: 253-262.

[20] Chen KS. Estimation of the process incapability index. Communications in Statistics: Theory and Methods. 1998; 27(5):1263-1274.

[21] Farnum NR. Using Johnson curves to describe Non-normal process Data. Quality Engineering. (1996-1997); 9: 329-336.

[22] Vannman K. A unified approach to capability indices. Statistica Sinica, 1995; 5: 805-820.

[23] Chang PL. Lu KH. PCI calculations for any shape of distribution with percentile. Quality World, technical section. 1994; September 110-114.

[24] Pearn WL, Chen KS. Estimating process capability indices for nonnormal Pearsonian populations. Quality and Reliability Engineering International 1995; 11: 386-388.

[25] Chou YM, Turner S. Henson S. Mayer D and Chen KS. On using percentiles to fit data by a Johnson distribution. Communication in Statistics-simulation and Computation. 1998; 23:314-354

[26] Polansky AM, Chou YM, Mason RL. Transforming non-normal data to normality in statistical process control, Journal of Quality Technology 1998; 30: 133-140.

[27] Bowmen KO. Shenton LR. Johnson's system of distributions. Encyclopedia of Statistical Sciences. 1983; 4: 303-314.

[28] Johnson L. Kotz. S. Balakrishnan N. Continuous Univariate Distribution Vol. 1. John Wiley \& Sons, New York, NY.

[29] Stuart A, ORD JK. Kendall's Advanced Theory of Statistics 1(5) Oxford University press, New York, NY. 1987

[30] Kendall MG, Stuart A. The Advanced Theory of Statistics, Vol 1. Macmillan: New York.1977

[31] Draper J. Properties of distributions resulting from certain simple transformation of the Normal distribution. Biometrika.1952; 39: 290301.

[32] Slifker JF, Shapiro SS. The Johnson system: selection and parameter estimation. Technometrics 1980; 22: 238-246.

[33] Wheeler RE. Quantile estimators of Johnson curve parameters. Biometrika. 1980; 67: 725- 728 